Editorial

\title{
Structural Health Monitoring of Large Structures Using Acoustic Emission-Case Histories
}

\author{
Kanji Ono \\ Department of Materials Science and Engineering, University of California, Los Angeles (UCLA), \\ Los Angeles, CA 90095, USA; ono@ucla.edu
}

Received: 13 October 2019; Accepted: 16 October 2019; Published: 29 October 2019

\section{Introduction}

Acoustic emission (AE) techniques have successfully been used for assuring the structural integrity of large rocket motorcases since 1963 [1], and their uses have been expanded to ever larger structures [2,3], especially since the structural health monitoring (SHM) of large structures has become an urgent task for engineering communities globally. The needs for advanced methods of AE monitoring are felt most keenly by those dealing with aging infrastructure. Many publications have appeared covering various aspects of $\mathrm{AE}$ techniques, but documentation of actual applications of $\mathrm{AE}$ techniques has been limited mostly to reports of successful results without technical details that allow objective evaluation of the results, except for some exceptions in the literature where special applications were detailed [4-6]. In this Special Issue of the Acoustics section of Applied Sciences, we sought contributions, like the exceptions cited here, which describe case histories of AE being applied to large structures. That is, papers that have achieved the goals of SHM and do so by giving adequate technical information supporting the success stories. Gathered here are 14 such articles that cover structures from aerospace and geological structures, bridges, buildings, factories, nuclear facilities, etc.

\section{Acoustic Emission Applications}

With the goal given above, this special issue was initiated to collect latest research on relevant subjects. There were 28 papers submitted to this special issue, and 14 papers were accepted (i.e., a 50\% acceptance rate). A key review paper, authored by Manthei and Plenkars [7], covered AE applications for the SHM of mines and in various geological settings. Of these, underground repositories for nuclear waste are especially significant, and millimeter-size defects were located in a million cubic meter volume, demonstrating in situ AE monitoring is a useful tool to observe instabilities in rock long before any damage becomes visible. Moriya [8] presented the use of an AE method for determining the seismicity of a lake bottom following the massive 2011 Tohoku earthquake. Another review by Behnia et al. [9] discussed AE methods for evaluating the structural integrity of asphalt pavements located in cold regions. It amply shows that $\mathrm{AE}$ allows for relatively rapid and inexpensive characterization of pavement materials and can be used for enhancing pavement sustainability and resiliency to thermal loading.

Three papers dealt with the SHM of industrial structures, bridges, and masonry buildings. Elizarov et al. [10] presented a series of examples of AE monitoring of industrial facilities under load, both static and fatigue conditions. Some were one of a kind structures, forcing them to improvise various techniques. They successfully evaluated oil refinery tanks and towers, pipelines, rotary kilns, bridge structures, drag lines, etc. Swit [11] also covered AE detection of active destructive processes that are in progress on various structures, including steel bridges, steel columns, and a large suspension bridge. The use of pattern recognition analysis was effective in identifying active damage progression. Carpinteri et al. [12] detected AEs from seismically induced cracking in an ancient building. 
Work by Esola et al. [13] was directed at the evaluation of aerospace composite parts via AE monitoring. They developed a multi-dimensional parts assessment method by taking advantage of $\mathrm{AE}$ data recorded during structural testing. For this goal, they tested 16 composite fixed-wing-aircraft spars using a structural loading sequence designed around a manufacturer-specified design limit load (DLL). While loading, the Felicity ratio was calculated. Along with specific AE data from post-processing, they deduced spar test classification in terms of apparent damage behavior.

In applications aimed toward the SHM of concrete structures, the Ziehl group presented two studies [14,15]. In the first one, Abdelrahman et al. [14] applied remote AE monitoring on an actively corroding concrete structure for one year and showed the feasibility of using AE for corrosion damage detection and classification. Here, studies of decommissioned components and control concrete parts were examined in parallel and comparative evaluation led to the conclusion. In the second study, Soltangharaei et al. [15] examined alkali-silicate reaction on large-scale concrete structures. They utilized an agglomerative hierarchical algorithm to classify the AE data based on energy-frequency based features. AE observations were correlated to confinement strains, allowing the assessment of structural degradation via AE signal features.

In all AE applications, source location is essential and Zhou et al. [16] proposed a new scheme for dealing with outliers, by introducing a preconditioned closed-form solution based on weight estimation. While this produced improvements, some real effects like damage-induced velocity variation still needs additional study, as noted by the authors. Zhong et al. [17] provided another approach for improving source location accuracy. This is called multiple signal classification (MUSIC), which adds directional scanning ability and easy arrangement of the sensor array. This approach takes advantage of Lamb wave propagation behavior, focusing on identified center frequency. This work further combined optimized ensemble empirical mode decomposition (EEMD) and a two-dimensional multiple signal classification algorithm for real-time impact localization on composite structures. This new method was validated on a cross-ply composite plate.

Another improvement in AE data analysis was given by Keshtgar et al. [18] through a statistical concept, Bayesian analysis. They considered AE data during fatigue monitoring of crack growth. Hong et al. [19] gave an analysis of transverse vibration on a beam that may be useful in preventing damages to high-rate systems.

Lastly, a review paper by the present author, 'Review on structural health evaluation with acoustic emission' [3] gave an overview of the current status of AE contribution to SHM. This article first examined signal attenuation, since any AE application seeks minimizing the number of sensors. It is shown that signal loss from geometrical spreading is a key issue in many shell-type structures. Another issue is general lack of attenuation data, found after an extensive survey of existing experimental reports. Since theory cannot provide such attenuation data, more effort is needed before quantitative SHM design procedures can be implemented. This is followed by discussion on source location, bridge monitoring, sensing and signal processing, pressure vessels and tanks, and special applications.

\section{Future on AE-SHM}

Although this special issue has been closed, more research and development work in $\mathrm{AE}$ technologies useful for SHM is in progress. It can be anticipated that future SHM will benefit from advanced AE applications that take advantage of various modeling tools and artificial intelligence technologies. Newer, smaller sensors, remote monitoring, feature and clustering analyses, and $\mathrm{AE}$ monitoring in extreme environments are some of anticipated topics to come. More effective AE methods are required more than ever for sustainable societies.

Acknowledgments: This issue was made successful by the contributions of all the talented authors. Also essential were gracious and professional reviewers, who gave the feedback, valuable comments, and suggestions. Thank you. I am particularly grateful to fellow Guest Editors, Marvin Hamstad, Tomoki Shiotani, and Martine Wevers for their contributions. Finally, thanks are due to the dedicated editorial team of Applied Sciences and special thanks to Daria Shi from MDPI Branch Office, Beijing, who helped guide this issue to its successful conclusion. 


\section{References}

1. Green, A.T.; Lockman, C.S.; Steele, R.K. Modern Plastics; Breskin Publications Inc.: New York, NY, USA, 1964; Volume 41, pp. 137-139.

2. Ono, K. Application of Acoustic Emission for Structure Diagnosis. Diagnostics 2011, 2, 3-18.

3. Ono, K. Review on Structural Health Evaluation with Acoustic Emission. Appl. Sci. 2018, 8, 958. [CrossRef]

4. Anonymous. MONPAC Technology. J. Acoust. Emiss. 1986, 8, 1-34.

5. Hay, D.R.; Cavaco, J.A.; Mustafa, V. Monitoring the Civil Infrastructure with Acoustic Emission: Bridge Case Studies. J. Acoust. Emiss. 2009, 27, 1-9.

6. Gorman, M.R.; Modal, A.E. Analysis of Fracture and Failure in Composite Materials, and the Quality and Life of High Pressure Composite Pressure Vessels. J. Acoust. Emiss. 2011, 29, 1-28.

7. Manthei, G.; Plenkers, K. Review on In Situ Acoustic Emission Monitoring in the Context of Structural Health Monitoring in Mines. Appl. Sci. 2018, 8, 1595. [CrossRef]

8. Moriya, H. Acoustic Emission/Seismicity at Depth Beneath an Artificial Lake after the 2011 Tohoku Earthquake. Appl. Sci. 2018, 8, 1407. [CrossRef]

9. Behnia, B.; Buttlar, W.; Reis, H. Evaluation of Low-Temperature Cracking Performance of Asphalt Pavements Using Acoustic Emission: A Review. Appl. Sci. 2018, 8, 306. [CrossRef]

10. Elizarov, S.; Barat, V.; Terentyev, D.; Kostenko, P.; Bardakov, V.; Alyakritsky, A.; Koltsov, V.; Trofimov, P. Acoustic Emission Monitoring of Industrial Facilities under Static and Cyclic Loading. Appl. Sci. 2018, 8, 1228. [CrossRef]

11. Swit, G. Acoustic Emission Method for Locating and Identifying Active Destructive Processes in Operating Facilities. Appl. Sci. 2018, 8, 1295. [CrossRef]

12. Carpinteri, A.; Niccolini, G.; Lacidogna, G. Time Series Analysis of Acoustic Emissions in the Asinelli Tower during Local Seismic Activity. Appl. Sci. 2018, 8, 1012. [CrossRef]

13. Esola, S.; Wisner, B.; Vanniamparambil, P.; Geriguis, J.; Kontsos, A. Part Qualification Methodology for Composite Aircraft Components using Acoustic Emission Monitoring. Appl. Sci. 2018, 8, 1490. [CrossRef]

14. Abdelrahman, M.; ElBatanouny, M.; Dixon, K.; Serrato, M.; Ziehl, P. Remote Monitoring and Evaluation of Damage at a Decommissioned Nuclear Facility using Acoustic Emission. Appl. Sci. 2018, 8, 1663. [CrossRef]

15. Soltangharaei, V.; Anay, R.; Hayes, N.; Assi, L.; Le Pape, Y.; Ma, Z.; Ziehl, P. Damage Mechanism Evaluation of Large-Scale Concrete Structures Affected by Alkali-Silica Reaction Using Acoustic Emission. Appl. Sci. 2018, 8, 2148. [CrossRef]

16. Zhou, Z.; Rui, Y.; Zhou, J.; Dong, L.; Chen, L.; Cai, X.; Cheng, R. A New Closed-Form Solution for Acoustic Emission Source Location in the Presence of Outliers. Appl. Sci. 2018, 8, 949. [CrossRef]

17. Zhong, Y.; Xiang, J.; Chen, X.; Jiang, Y.; Pang, J. Multiple Signal Classification-Based Impact Localization in Composite Structures Using Optimized Ensemble Empirical Mode Decomposition. Appl. Sci. 2018, 8, 1447. [CrossRef]

18. Keshtgar, A.; Sauerbrunn, C.; Modarres, M. Structural Reliability Prediction Using Acoustic Emission-Based Modeling of Fatigue Crack Growth. Appl. Sci. 2018, 8, 1225. [CrossRef]

19. Hong, J.; Dodson, J.; Laflamme, S.; Downey, A. Transverse Vibration of Clamped-Pinned-Free Beam with Mass at Free End. Appl. Sci. 2019, 9, 2996. [CrossRef]

(C) 2019 by the author. Licensee MDPI, Basel, Switzerland. This article is an open access article distributed under the terms and conditions of the Creative Commons Attribution (CC BY) license (http://creativecommons.org/licenses/by/4.0/). 